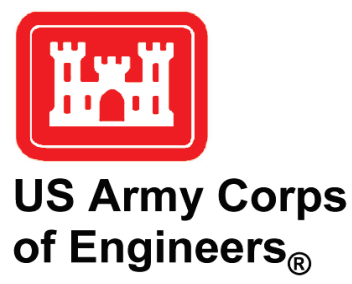

\title{
Identification of Challenges and Opportunities for Regional Sediment Management (RSM) and Engineering With Nature (EWN) within Inland USACE Districts
}

\section{by Katherine Touzinsky, Paul Boyd, and John Shelley}

PURPOSE: The purpose of this Coastal and Hydraulics Engineering Technical Note (CHETN) is to summarize the initial findings of a technical workshop entitled "Expanding Regional Sediment Management (RSM) and Engineering With Nature (EWN) to Integrate Inland Districts" held 29 April-1 May 2014 at the U.S. Army Corps of Engineers (USACE), Omaha District (NWO), in Omaha, Nebraska. This effort was undertaken to (a) initiate collaborative partnerships, (b) identify both challenges and opportunities in incorporating RSM and EWN into inland river, reservoir, and watershed systems, and (c) provide direction for future efforts in ensuring that RSM and EWN strategies are successful.

BACKGROUND: RSM refers to the effective utilization of littoral, estuarine, and riverine sediment resources in an environmentally effective and economical manner (Rosati et al. 2001 [rev. 2004]). RSM is a systems-based approach that is implemented collaboratively with other Federal, state, and local agencies. The central goal of the USACE RSM Program is to support sustainable solutions for the USACE Navigation, Flood Risk Management, and Environmental Restoration missions by maintaining or enhancing the natural exchange of sediment within the boundaries of the physical system. To accomplish that goal, the focus of engineering activities must be shifted from local or project-specific to a larger scale, as defined by natural processes. RSM goals align with EWN, a program that was established in 2010 as an approach to facilitate commercial navigation and safe communities and to restore aquatic ecosystems in an environmentally and economically sustainable fashion. By definition, EWN is the intentional alignment of natural and engineering processes to efficiently and sustainably deliver economic, environmental, and social benefits through collaborative processes.

The USACE RSM Program was initiated in 1999 through a charge from the Coastal Engineering Research Board to implement regional approaches to improve the management and use of sediments across multiple projects and USACE business lines while collaboratively working with stakeholders and partners in decision making (Lillycrop et al. 2011). Therefore, throughout the first decade of the RSM program, the primary focus was with USACE coastal Districts to consider sediments as valuable resources and keep sediments in the littoral system to restore natural sediment transport processes rather than placing them offshore or in upland placement sites. Initially, sediment dredging activities in support of navigation channel maintenance with resultant direct beach placement or nearshore placement were common actions, with a focus on the beneficial use of dredge material. While inland Districts sporadically participated in the program during the first decade, an increased focus on inland Districts and inland sediment management issues was initiated in 2010. While there had been increased involvement in the 
program, challenges with the RSM program goals and funding framework had limited full participation. With many inland districts not having active dredging or navigation channel maintenance programs, there were limited opportunities for beneficial use of dredge material.

Initial discussions on developing guidelines for integration of inland systems began with the RSM leadership team in 2010-2011, and interest from inland Districts has grown significantly in the last few years.

WORKSHOP OVERVIEW: The workshop on "Expanding Regional Sediment Management (RSM) and Engineering with Nature (EWN) to Integrate Inland Districts" was held 29 April-1 May 2014 at NWO in Omaha, NE. There were approximately 20 participants representing NWO, Huntington (CELRH), Kansas City (CENWK), Louisville (CELRL), Rock Island (CEMVR), St. Louis (CEMVS), and St. Paul Districts (CEMVP); the U.S. Army Engineer Research and Development Center (ERDC), Coastal and Hydraulics Laboratory (CHL), and Environmental Laboratory (EL); and the USACE Institute for Water Resources (IWR), Hydrologic Engineering Center (HEC).

The workshop included overviews of RSM and EWN, District projects that were supported through the RSM program or that included the principles and practices of RSM and EWN, District/ERDC/IWR-HEC numerical modeling and data collection capabilities, and sediment challenges in river and reservoir systems. In addition to the presentations, much effort was put into defining and refining the opportunities, challenges, and future direction for developing an RSM and EWN framework for river and reservoir systems. The workshop attendees also participated in a site visit to a shallow-water habitat project on the Missouri River that embodies many of the tenets of RSM and EWN.

An outcome of the workshop was a list of challenges and opportunities directly related to integrating and implementing RSM and EWN in inland Districts. The challenges and opportunities are summarized below.

\section{CHALLENGES}

- There is a general mischaracterization that "sediment is a pollutant" in systems whereas sediment is, in fact, an essential ecosystem component and resource. This mischaracterization leads to regulatory hurdles and unnecessarily drives up costs.

- There is a lack of data on inland river systems.

- There are no calibration data or reference reaches for inland river systems for either water or sediment.

- With decreasing budgets, suspended sediment is the first to be excluded from the monitoring list.

- When the scope is broadened to a watershed-level system, many unknown factors and a high degree of interconnectivity is introduced.

- As the focus of engineering activities is broadened in scope, conflicting sediment management objectives become revealed (e.g., stretches of the same river will experience differing issues associated with sediment accumulation or loss). 
- There is a lack of authorities, particularly relating to reservoir sediment management for water supply sustainability.

- States have limited budgets and are not interested in land purchase for infrastructure development projects.

- There are different environmental agency goals.

- There are environmental effects associated with reservoir drawdown for sediment management.

- Stakeholders are actively and often happily adapting to the systems that have aggradation, degradation, or delta formations (e.g., duck hunting and other recreational activities).

- Many studies have been completed regarding water but sediment analyses were not included.

- Reservoir sediments may not be an issue at every project. USACE does not currently have a complete picture of reservoir sedimentation but is in the process of developing better understanding.

- Discounting of future benefits to present value favors unsustainable development by ignoring the economics of exhaustible benefits (Hotelling 1931).

- Prospect courses on river engineering are not currently available.

- There is no overall inland group communication similar to the Coastal Working Group, a subcommunity of practice (COP) to the USACE Hydrology and Hydraulics COP.

\section{OPPORTUNITIES}

- Develop technical guidance for selection and design of Best Management Practices (BMPs) for watershed and stream channel erosion prevention.

- Identify sediment resources and flux in and out of the flood plain and create sediment budgets using the Sediment Budget Analysis System (SBAS) (Rosati and Kraus 1999, 2001 [rev. 2003]) or the Sediment Impact Analysis Methods (SIAM) (Gibson and Little 2006; Little and Jonas 2010).

- Establish a program for review of completed channel restoration projects similar to the USACE Monitoring Completed Navigation Projects (MCNP) Program.

- Investigate guidance and lessons learned regarding bendway weirs and grade control structures.

- Create a formal watershed authority to implement projects quickly.

- Offer prospect courses or apprenticeship opportunities.

- River engineering associates program.

- Reservoir sediment management.

- Quantify costs and benefits of removing and discharging sediments from reservoirs versus costs to store sediments in reservoirs.

- Quantify costs for beneficial use plans that keep sediment in the river.

- Quantify losses during emergency events and relate those losses to loss of habitat.

- Prepare strategies for sediment management utilizing natural processes in advance of emergency events.

The brainstorming sessions in this workshop developed many ideas and opportunities to integrate RSM and EWN into inland and reservoir systems. As a follow-on discussion, the workshop 
participants considered actions that could be taken to expand RSM and EWN project activities in the inland Districts.

FUTURE DIRECTION: Actions identified by the workshop were consolidated into six major categories:

1. Create a guide to outline basic technical ideas integrating RSM, EWN, and USACE interests of sustainability, resilience, navigability, and infrastructure. This should be structured with enough flexibility to capture variance depending on the project or District. Additionally, the tenets and/or guidance for RSM and EWN would be revisited to include points regarding how they apply to inland watersheds/river/reservoirs. The accounting procedure should be updated to include benefits associated with nondredged material.

2. Prepare a technical paper (white paper) on the benefits of sediment as a resource to begin the conversation to change state and public opinion. It should feature an environmental perspective to highlight the net benefit of additional sediment downstream. This could aggressively challenge mental models and regulatory frameworks that sediment in a river is a pollutant/problem. This paper would be intended to lead to case studies and eventually RSM and EWN projects.

3. Create problem/keyword-searchable technical descriptions of RSM and EWN projects to allow expansion of, and building upon, previous work with inland sediments.

4. Revisit former USACE sediment management projects and make performance assessments.

5. Develop a framework to determine the long-term costs of sedimentation in reservoirs and impacts to downdrift systems, to become more knowledgeable regarding costs.

6. Broader research and development is needed for decreasing level of effort in implementing river models. Sediment modeling as a technical specialty is limited in its application to current integrated watershed problems, primarily watersheds that include reservoirs. The expansion and integration of sediment transport tools (new and existing) to include watersheds, rivers, and reservoirs would constitute a significant step in the ability to evaluate sediment in a watershed as a whole.

While these six categories are certainly not the only actions to be considered, the development of any or all of them would be a significant step toward integrating inland rivers, reservoirs, and watersheds into and RSM and EWN framework.

LESSONS LEARNED AND PROBLEMS ENCOUNTERED: In addition to the 2 days of discussions and brainstorming (Figure 1), the workshop also included a field trip to an active construction site where shallow-water habitat was being constructed in support of pallid sturgeon recovery. 


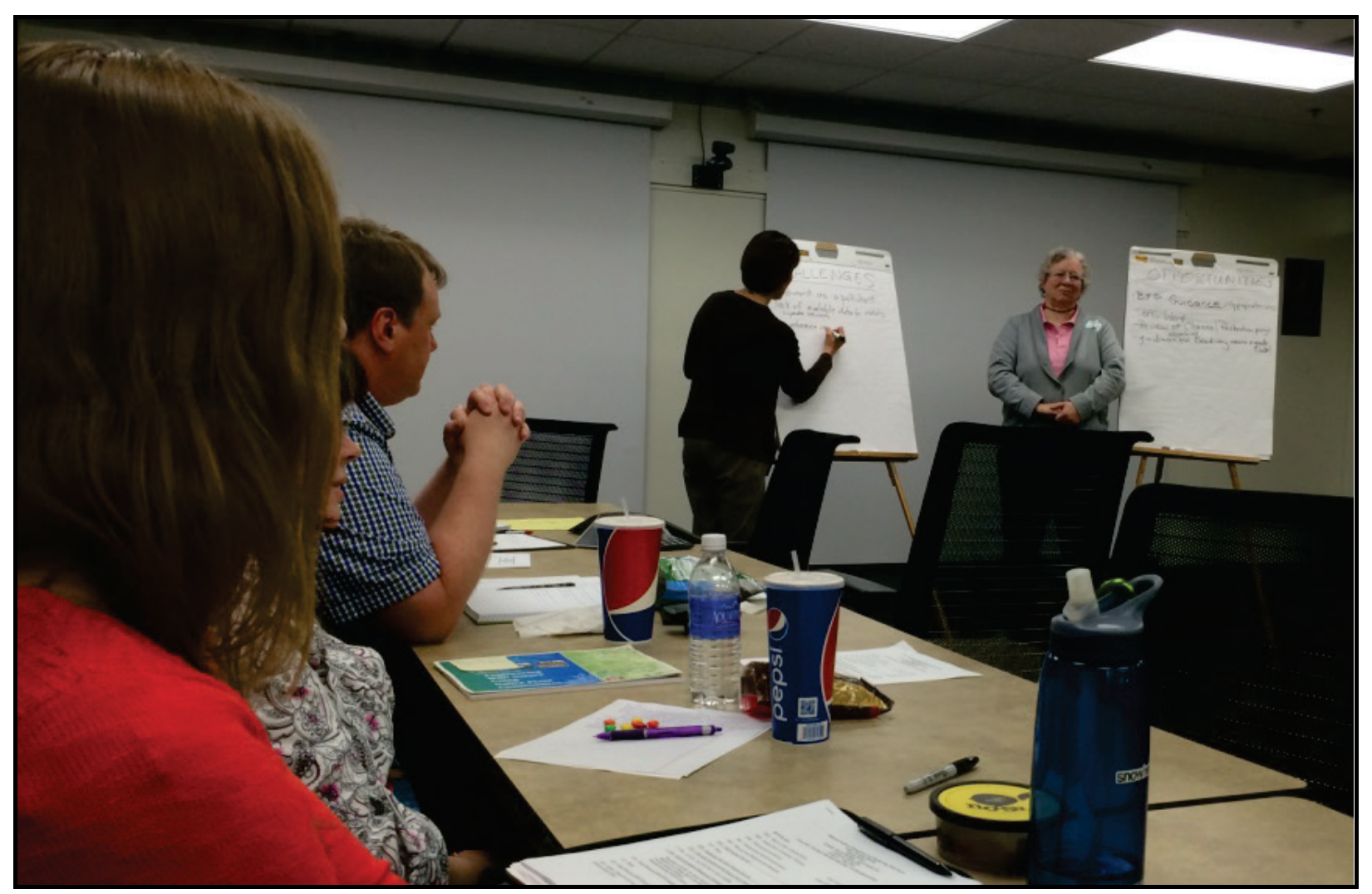

Figure 1. Inland RSM and EWN workshop brainstorming session.

Lessons learned from the workshop discussions and the field trip could be grouped into three major areas: (1) Ongoing projects that could already be considered inland RSM and EWN, (2) resource and data limitations that prevent identification of the benefits associated with inland RSM and EWN projects, and (3) current guidance limitations that do not directly support RSM with movement of sediment. The expansion of the RSM and EWN guidance to specifically address inland sediment issues would increase the applicability of the program to all USACE Districts.

The participants found through the workshop discussions that many projects being undertaken by Districts could already be considered RSM and EWN based on their goals and processes. As an example, the Shallow Water Habitat (SWH) project at Deer Island on the Missouri River is developing pallid sturgeon habitat through mechanical construction and dredging along the navigation channel of the river (Figure 2). This project, and many like it, already employ the tenets of RSM and EWN but have not been categorized as such in the past.

This example shows that there are likely dozens of projects ongoing in USACE that could be considered RSM and EWN, and an effort to catalog these projects and include them in a discussion of inland RSM and EWN would show how much progress has already been made. Categories 3 and 4 could be directly supported by simply inventorying existing USACE projects with RSM and EWN fundamentals. 


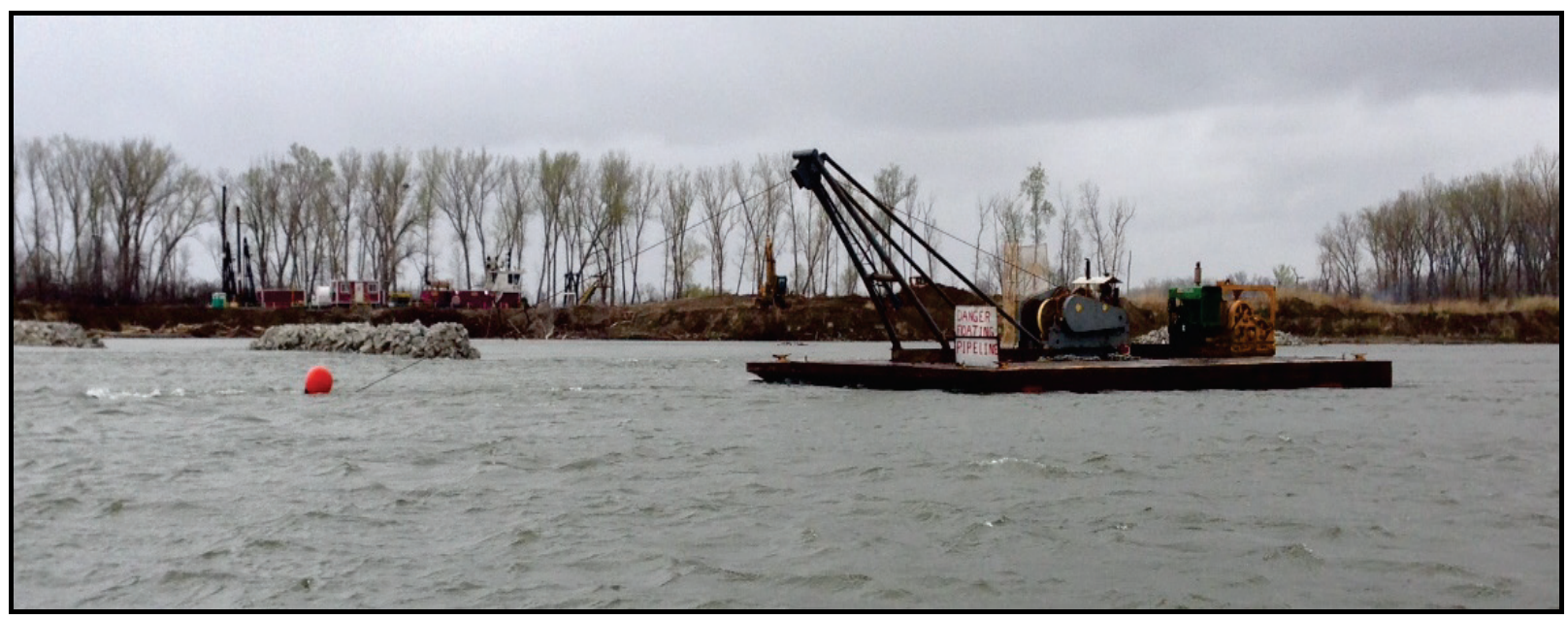

Figure 2. Dredging to construct shallow-water habitat at the Deer Island project (Missouri River, above Omaha, NE).

One of the primary ways to show the success of RSM and EWN projects is to determine benefits to the USACE Business Lines associated with the project. The physical extents of the project often have an influence on the level of data collected to show those benefits. For the example of a beach nourishment project, there is an evaluation of the sediment source, sediment placement, and regional benefits of placement.

When considering inland RSM and EWN systems that include watersheds, rivers, and reservoirs, regional can often extend hundreds of miles when assessing benefits and impacts. The data to assess these benefits are widely dispersed and sometimes nonexistent. An accurate assessment of the benefits requires an increase in the visibility of the existing data, a sharing of the data freely, and an expansion of data collection where gaps exist.

Because the USACE RSM Program is an Operations and Maintenance-funded program, historically RSM has been connected with the idea of beneficial use of dredge material as a way to quantify the benefits of a regional approach to sediment management. For inland Districts, many of whom have very limited or no dredging programs, this has been an obstacle to participation in the program. To be able to fully integrate inland Districts into RSM, management to prevent dredging and sediment deposition needs to be considered a benefit to the project, not just beneficial use of material once it has been deposited. This concept has since been incorporated into the RSM framework.

CONCLUSIONS AND RECOMMENDATIONS: The inland RSM and EWN workshop opened dialogue regarding how inland projects are regionally connected and linked to coastal projects and identified areas where additional work is needed to integrate projects with the inland program.

Based on workshop dialogue regarding Challenges and Opportunities, a set of future action items was developed. These action items are the first steps in expanding RSM and EWN to include reservoir and riverine systems all the way to the coasts. 
The process of integrating RSM and EWN into inland systems will require a series of additional workshops and projects. To start that process, the six outlined categories of actions developed by this present workshop were combined into four directives for assessment in the short term.

1. Revisit the RSM guidance and identify opportunities to integrate inland watershed/river/reservoir systems and identify benefits from managing these projects that many not be directly connected with beneficial use of dredge material. Write up this review with accompanying case studies to show nontraditional benefits and include a discussion of sediment as a resource instead of a pollutant.

2. Survey existing USACE projects that are associated with sediment management to develop a list of examples where inland RSM and EWN principles and practices are already being used. Integrate this information with coastal projects to create a searchable database for RSM and EWN.

3. Examine the development of an ERDC/HEC program to integrate watershed, river, reservoir, and costal modeling tools to holistically evaluate sediment fate and transport.

4. Conduct an annual inland District RSM working meeting as a breakout session in conjunction with the annual USACE RSM In-Progress Review and working group meetings.

ADDITIONAL INFORMATION: This Coastal and Hydraulics Engineering Technical Note (CHETN) was prepared as part of the USACE Regional Sediment Management (RSM) Program. This CHETN was written by Katherine Touzinsky, ERDC-CHL; Paul Boyd, Omaha District (NWO); and John Shelley, Kansas City District (NWK). Additional information pertaining to the RSM Program can be found on the RSM website http://rsm.usace.army.mil. This document can be accessed on the RSM website and on the USACE Engineering With Nature (EWN) initiative website http://el.erdc.usace.army.mil/ewn/.

Questions pertaining to this CHETN may be addressed to the following:

Paul M. Boyd, P.E.

Paul.M.Boyd@usace.army.mil

(USACE NWO RSM Lead)

John Shelley, P.E.

John.Shelley@usace.army.mil

(USACE NWK RSM Lead

Linda Lillycrop

Linda.S.Lillycrop@usace.army.mil

(USACE RSM Program Manager)

Dr. Todd Bridges

Todd.S.Bridges@usace.army.mil

(USACE EWN Program Manager) 
This CHETN should be cited as follows:

Touzinsky, K., P. Boyd, and J. Shelley. 2016. Identification of challenges and opportunities for Regional Sediment Management (RSM) and Engineering With Nature (EWN) within inland USACE districts. ERDC/CHL CHETN-XIV-53. Vicksburg, MS: U.S. Army Engineer Research and Development Center.

\section{REFERENCES}

Gibson, S. A., and C. Little. 2006. Implementation of the sediment impact analysis methods (SIAM) in HEC-RAS. In Proceedings, Eighth Joint Federal Interagency Sedimentation Conference. Reno, NV.

Hotelling, H. 1931. The economics of exhaustible resources. The Journal of Political Economy 39(2):137-175.

Lillycrop, L. S., J. W. McCormick, L. E. Parson, and M. A. Chasten. 2011. Adaptive management through regional sediment management. In Proceedings of the Western Dredging Association (WEDA XXXI) Technical Conference and Texas A\&M University (TAMU 42) Dredging Seminar, 178-187. Nashville, TN.

Little, C., and M. Jonas. 2010. Sediment impact analysis methods (SIAM): Overview of model, capabilities, applications, and limitations. In Proceedings, Second Joint Federal Interagency Sedimentation Conference. Las Vegas, NV.

Rosati, J. D., B. D. Carlson, J. E. Davis, and T. D. Smith. 2001 (rev. 2004). The Corps of Engineers national regional sediment management demonstration program. ERDC/CHL CHETN-XIV-1. Vicksburg, MS: U.S. Army Engineer Research and Development Center. http://chl.erdc.usace.army.mil/library/publications/ chetn/pdf/chetn-xiv-1.pdf

Rosati, J. D., and N. C. Kraus. 1999. Sediment budget analysis system (SBAS). Coastal Engineering Technical Note IV-20. Vicksburg, MS: U.S. Army Engineer Research and Development Center. http://chl.erdc.usace.army.mil/ library/publications/chetn/pdf/cetn-iv-20.pdf

Rosati, J. D., and N. C. Kraus. 2001 (rev. 2003). Sediment budget analysis system (SBAS): Upgrade for regional applications. ERDC/CHL CHETN-XIV-3. Vicksburg, MS: U.S. Army Engineer Research and Development Center. http://chl.erdc.usace.army.mil/library/publications/chetn/pdf/chetn-xiv-3.pdf 


\section{ACRONYMS AND ABBREVIATIONS}

Term Definition

BMP Best Management Practice

CHETN Coastal and Hydraulics Engineering Technical Note

CHL Coastal and Hydraulics Laboratory

ERDC Engineer Research and Development Center

EWN Engineering With Nature

EL Environmental Laboratory

HEC Hydrologic Engineering Center

MCNP Monitoring Completed Navigation Projects

NWK U.S. Army Engineer District, Kansas City

NWO U.S. Army Engineer District, Omaha

RSM Regional Sediment Management

USACE U.S. Army Corps of Engineers

NOTE: The contents of this technical note are not to be used for advertising, publication, or promotional purposes. Citation of trade names does not constitute an official endorsement or approval of the use of such products. 